(C) $<2017>$. This manuscript version is made available under the CC-BY-NC-ND 4.0

license http://creativecommons.org/licenses/by-nc-nd/4.0/

DOI: https://doi.org/10.1016/j.shpsa.2017.06.001

\title{
Duhemian good sense and agent reliabilism
}

\section{Background and Introduction}

Famously, according to Pierre Duhem a hypothesis can never be experimentally tested in isolation, but only along with the entire theoretical scaffolding it comes with. So in the face of disagreement between theory and experiment, it is impossible to point out which hypotheses in the theory are flawed. A big question for Duhem was, how does the physicist act in such a situation of underdetermination? Which hypotheses does she discard, and which one(s) does she retain? Duhem's response was that the physicist possesses a partly intuitive, partly cultivated, "good sense" that directs this choice. For him, although good sense does not provide a rigorous, rule-based template for theory choice ${ }^{1}$, it allows scientists to weigh evidence and be "fair and impartial" $(1954,218)$.

Recently, there has been much interest in drawing parallels between Duhem's good sense and ideas in virtue epistemology (VE). VE emerged in the 1980s as an approach to epistemology analogous to virtue ethics. In the words of John Greco and John Turri (2016): "Virtue ethics explains an action's moral properties in terms of the agent's properties, for instance whether it

\footnotetext{
${ }^{1}$ While "theory choice" today is generally understood in the context of contrastive underdetermination, Duhem was primarily concerned with the holist variety of underdetermination and advanced good sense in the context of the latter. But for the purposes of this paper the distinction will not matter (with the exception of one small discussion in Section 4 where I shall clarify the distinction), and I shall use "theory choice" to refer to underdetermination in general, as do all the authors I reference.
} 
results from kindness or spite. VE explains a cognitive performance's normative properties in terms of the cognizer's properties, for instance whether a belief results from hastiness or excellent eyesight, or whether an inquiry manifests carelessness or discrimination. For virtue ethics the relevant properties are moral virtues and vices, and for VE intellectual virtues and vices.” A virtue epistemological reading of good sense as first advanced by David Stump (2007) is based on the idea that Duhem too emphasized the normative properties of the scientist qua cognitive agent and took them as a basis for legitimate scientific knowledge in the face of underdetermination of theory by evidence. Stump finds striking similarities particularly between Duhemian good sense and Linda Zagzebski’s views of VE. Milena Ivanova (2010) and Abrol Fairweather (2011) have proposed interesting critical responses to Stump's view. Here, I discuss the views of Stump, Ivanova, and Fairweather in this regard and ultimately propose my own view in response, which is an agent-reliabilist reading of Duhem's good sense.

In Section 2 I give overviews of Stump's, Ivanova's, and Fairweather's views, and briefly describe my responses to them. In Section 3 I describe in some detail Greco's (1999) version of agent reliabilism. In Section 4 I show how Duhem nicely fits this picture of agent reliabilism, and I close with Section 5 where I explore some larger implications of viewing Duhemian good sense as agent reliabilist, to the Problem of Induction in philosophy of science.

\section{Three Tales of Good Sense}

Stump (2007) argues that Duhem conceived of good sense in a way that can today be understood as virtue theoretic. In particular, Stump finds similarities between good sense and ideas of VE put forward by Zagzebski (1996). As Stump tells us, Zagzebski argued that justified belief comes from a "cluster of intellectual virtues in the same way that the rightness of an act 
can be defined in terms of moral virtue in ethical theory"(Stump, 151). Stump argues that Duhem's good sense nicely fits in with these ideas. Good sense depends on the scientist, the cognitive agent, being "virtuous": she has to be, in the words of Duhem quoting Claude Bernard, a "faithful and impartial judge". Stump further provides another illuminating quote from Duhem from his lectures on German science:

"In the realm of every science, but more particularly in the realm of history, the pursuit of the truth not only requires intellectual abilities, but also calls for moral qualities: rectitude, probity, detachment from all interest and all passions.” (Duhem quoted in Stump, 152). Stump notes that some of the epistemic virtues put forward by Zagzebski include intellectual sobriety, impartiality and intellectual courage and the list fits very well with Duhem's. Yet another striking similarity between Zagzebski and Duhem according to Stump is that they both appeal to non-rule-governed epistemology. Zagzebski, in making a case for an epistemology based on ethics, says, "The idea is that there can be no complete set of rules sufficient for giving a determinate answer to the question of what an agent should do in every situation of moral choice." (Stump, 152) Similarly, Duhem arrives at the idea of good sense when the rule-based epistemology of the physical method (i.e. strict agreement between theory and experiment) fails. As Stump says,

"Holism threatens to make testing impossible, yet Duhem believes that scientific consensus will emerge. While the pure logic of the testing situation leaves theory choice open, good sense does not. Duhem claims that the history of science shows that while there is controversy in science, there is also closure of scientific debates." (Stump, 155)

Ivanova (2010) has argued that Stump is mistaken in drawing such close parallels 
between VE and Duhem's good sense. Her central objection ${ }^{2}$ has to do with epistemic justification. According to her whereas VE takes epistemic virtues to be justifications for beliefs, Duhem did not invoke the concept of good sense to justify belief in one theory over another. (She rightly notes that Duhem did not have a full-blown metaphysical notion of truth of a theory - but worked with the surrogate idea of truth, natural classification: a right theory approaches a transcendental, natural classification of experimental laws. So justification for belief in a theory here means justification for the belief that the said theory is approaching a natural classification, not for the belief that it is true.) Rather, she argues, good sense for Duhem was more a post hoc explanation of the physicist's choice: it explains the repeated success of theories at making novel predictions. According to Ivanova, what really justified belief in a theory for Duhem - i.e. the belief that it was approaching a natural classification - was the success of the theory in making correct novel predictions. She says that for Duhem, "[a scientist] is justified in believing that a theory is a natural classification only when some empirical evidence supports it or when the theory has become a 'prophet for us' (Duhem, 27), that is, when it has managed to make novel predictions." (Ivanova, 62). Moreover, according to Ivanova, Duhem doesn't say much about good sense as a method of science: he doesn't tell us how exactly it directs our choice. His account of how good sense comes about and works to direct theory choice is quite thin. For Ivanova, this further shows that Duhem did not introduce it as a justification but only as a post

\footnotetext{
${ }^{2}$ She raises another objection that the comparison breaks down since VE has to do with getting to truth - and considers it attainable - while Duhem isn't in the truth-business: physical theories only approach a 'natural classification' of observable phenomena - never actually getting there and don't reveal any underlying truths about nature. But she responds to this objection herself by saying that a) natural classification is still related to truth in that it reveals truths about the relations between observable phenomena even if not about unobservable phenomena, and $b$ ) one could strive towards an epistemic goal even if it isn't attainable. I'm on board with these responses. I would add in response to a) that even if we didn't look at natural classification as related to any kind of truth, we can still draw parallels with VE with respect to the means to attaining an epistemic end - be it truth or natural classification - regardless of the end itself.
} 
hoc explanation.

Fairweather (2011) has advanced a position on Duhemian good sense that is a hybrid of Ivanova's and Stump's views. Fairweather claims to draw upon an agent reliabilist VE to do this. While simple reliabilism as a theory of knowledge has it that knowledge and justification are based on reliable cognitive processes, according to agent reliabilism, knowledge and justification have their bases in stable and successful dispositions of the cognitive agent. According to Fairweather good sense results in a reliable process - and this process for him is the result of “skillful exercise of cognitive character" $(2011,143)$, hence apparently making his reading of Duhem agent reliabilist. Since Duhem's claim is that good sense has a great "track record" and always picks out a successful theory - i.e. a theory that inevitably correctly makes a novel prediction - good sense produces a theory approaching a natural classification (the equivalent in the Duhemian context, of knowledge in regular epistemology) by a reliable process. According to Fairweather's reading of Duhem good sense is a 'truth-promoting factor' regardless of whether the theory it picks out ultimately succeeds in novel prediction. Fairweather says it is “tracking evidentially important features of theories" $(2011,143)$ He claims that "If a belief P is the product of a reliable capacity or process this fact constitutes evidence in favor of P." (ibid., 143) This implies, "If the products of good sense reliably turn out to be supported by compelling new evidence, then being the product of good sense will be evidence for any theory with such a distinguished etiology." (ibid., 143) So, Fairweather says, it seems that "future evidence is not required to evidentially distinguish the theory chosen by good sense, because the reliability of good sense is itself evidence supporting that theory." (ibid., 143)

What epistemic role - if any - does novel predictive success play then? According to Fairweather, good sense confers uniqueness to a theory - which, according to him, no future 
evidence can confer due to underdetermination. That is, good sense picks out one unique theory during underdetermination and puts the rest out of the running. But after good sense has uniquely picked out a theory, it is a successful novel prediction that counts as evidence in favor of the chosen theory. For Fairweather then, this is the conclusion that follows from such a reading of good sense:

"This shows an interesting fact that new evidence in favor of a theory gives it a different epistemic standing depending on whether we are considering it alongside or independent of meaningful rivals. In the former case, new confirming evidence does not make a theory the determinate choice with fundamental epistemic standing. In the latter case, that same evidence determines theory choice and confers fundamental epistemic standing." (Fairweather, 144) So there are two "epistemic values and epistemic standings": uniqueness, which comes from good sense, and clinching evidential support from a successful novel prediction. This way, good sense alone does not confer "fundamental epistemic standing", and evidence alone cannot confer uniqueness. This account, which recognizes an important epistemic role for both good sense and new empirical evidence, Fairweather calls the "hybrid reading".

My own view is that Stump is right in reading Duhem as a virtue epistemologist. However, within VE, Fairweather is right that agent reliabilism particularly fits Duhem well. (I think he is also right in pointing out that Stump's account is more paradigmatic of responsibilist (as opposed to reliabilist) VE which is based on epistemic responsibilities of the agent.) I contend that Ivanova makes a category mistake in claiming that good sense is explanatory and not justificatory: while Duhem's thesis of good sense - the thesis that physicists are guided by good sense in their theory choice - explains how physicists choose theories in the face of underdetermination, according to this thesis, good sense itself is what brings about and justifies 
the choice. So while explanatoriness applies to the thesis here, providing justification applies to the object of that thesis, i.e. good sense. I contend that Duhem was both in the business of explanation and justification: while he provided the thesis of good sense to explain theory choice, the thesis says that good sense justifies a physicist's choice of theory - and Duhem took this thesis seriously. I will also show how this line has clear parallels with the larger discourse in epistemology, on reliabilism as a solution to skepticism.

Fairweather is right in that agent reliabilism best fits Duhem's views. But although he claims to give an agent reliabilist reading of good sense, I don't think he goes into this deeply enough. While he agrees that "good sense can be seen as the skillful exercise of cognitive character" (Faiarweather, 143), he ultimately claims that it is novel predictive success that confers "fundamental epistemic standing" on theory choice. I believe this is mistaken. On my reading of Duhem, good sense should be considered at least as epistemically fundamental as novel predictive success. I will argue that no 'hybrid reading' is required: I will argue that agent reliabilism - following Greco's (1999) account of it - fully accommodates Duhem. Moreover, I will argue that there is no tension in having both novel predictive success and good sense in the larger epistemological picture. The role of novel predictive success in lending epistemic legitimacy to a theory does not threaten an agent reliabilist reading of Duhem. Before getting into defending these claims, I will now provide an overview of Greco's agent reliabilism.

\section{Greco and Agent Reliabilism}

Greco (1999) explains how some form of reliabilism is necessary to avoid skepticism. Hume has shown us that there is no logical relation between our empirical beliefs and their evidence. His arguments (from the famed Problem of Induction) show that "if our evidence is indeed a 
reliable indication of the truth of our empirical beliefs, then this is at most a contingent fact about human cognition, rather than a function of any necessary relations, deductive or inductive, between evidence and belief." (Greco, 273) Hence, "any non-skeptical theory of knowledge has to be a version of reliabilism." (ibid., 274) Reliabilism gets us out of the Problem of Induction since it grounds justification and knowledge in reliable cognitive sources. In other words, if we want to avoid skepticism and knowledge is to be possible, we have to take it that our beliefs stem from a reliable cognitive source: a source that reliably generates accurate beliefs.

Simple reliabilism is the view that a belief is justified just in case it is formed via reliable processes. Here the proportion of true beliefs the process results in, over time, measures reliability. Greco argues that simple reliabilism is insufficient for two reasons:

1. An agent might form a belief via fleeting or strange processes: Greco starts by noting that "Reliabilism must somehow restrict the kind of reliable process that is able to ground knowledge, so as to rule out processes that are strange or fleeting." (ibid., 286) As an example of such processes, Greco discusses Alvin Platinga's "The case of the epistemically serendipitous lesion" where an agent has a rare kind of a brain lesion, one that makes her believe that she has a brain lesion. There is no evidence for the lesion: there are no symptoms, no testimony etc.; in fact there might even be a lot of evidence against it. But the agent is unable to take account of this (lack of) evidence due to the lesion. The relevant cognitive process here must no doubt be deemed very reliable, but we would not want to take the resulting belief as justified.

2. Process reliabilism doesn't guarantee that the agent has a subjective justification of her belief. Greco says, 
"[there] is a powerful intuition that knowledge does require that the knower have some kind of sensitivity to the reliability of her evidence. Sometimes this intuition is expressed by insisting that knowledge requires subjective justification. It is not enough that one's belief is formed in a way that is objectively reliable; one's belief must be formed in a way that is subjectively appropriate as well.” (ibid., 285)

In other words, it should be an epistemological requirement that the epistemic agent not be oblivious to the reliability of her evidence. Simple reliabilism is okay with this obliviousness: it does not demand sensitivity to the reliability of one's evidence and is hence inadequate.

Greco's solution to the above problems is agent reliabilism. According to agent reliabilism, reliability is shifted from the belief-forming process to the qualities of the agent's mind:

"Relevant to present purposes is Sosa's suggestion for a restriction on reliable cognitive processes; it is those processes that have their bases in the stable and successful dispositions of the believer that are relevant for knowledge and justification. Just as the moral rightness of an action can be understood in terms of the stable dispositions or character of the moral agent, the epistemic rightness of a belief can be understood in terms of the intellectual character of the cognizer." (ibid., 287)

Following Ernest Sosa's views, Greco proposes that "knowledge and justified belief are grounded in stable and reliable cognitive character."(ibid., 287) Accordingly, "We may now explicitly revise simple reliabilism as follows: A belief $\mathrm{p}$ has positive epistemic status for a person $\mathrm{S}$ just in case $\mathrm{S}$ 's believing p results from stable and reliable dispositions that make up S's cognitive character." (ibid., 287) Agent reliabilism's focus is on how true beliefs are come to be had: it is through stable dispositions of the epistemic agent. Hence agent reliabilism effectively 
weeds out the brain lesion type cases: such beliefs are not come to be had by means of stable and reliable dispositions.

Greco proceeds to show how agent reliabilism also solves the problem of subjective justification:

VJ: "A belief $\mathrm{p}$ is subjectively justified for a person S (in the sense relevant for having knowledge) if and only if S's believing $\mathrm{p}$ is grounded in the cognitive dispositions that $\mathrm{S}$ manifests when $\mathrm{S}$ is thinking conscientiously.” (ibid., 289)

By "thinking conscientiously", Greco clarifies that he does not mean thinking with the purpose of finding truth, but rather the "usual state that people are in as a kind of a default mode - the state of trying to form beliefs accurately." Greco contrasts this with epistemic "vices" such as trying to comfort oneself or trying to seek attention.

Greco points out that agent reliabilism reverses the "usual direction of analysis between virtuous character and justified belief" (ibid., 290). While non virtue theoretic epistemologies understand virtues in terms of justified belief, here justified belief is being cached out in terms of virtues of the cognizer. "Virtuous belief is associated with the dispositions a person manifests when she is sincerely trying to believe what is true", and "The dispositions that a person manifests when she is thinking conscientiously are stable properties of her character, and are therefore in an important sense hers." (ibid., 290) Therefore, a belief formed this way will be subjectively appropriate.

To sum up, in order to avoid skepticism we need some form of reliabilism. Simple reliabilism runs into problems as above - hence agent reliabilism is the way to go. 


\section{Duhemian Good Sense and Agent Reliabilism}

First I want to draw the reader's attention to Duhem's characterization of the different kinds of minds - in Aim and Structure (1954), but also in detail in German Science (1991). The "ample but weak" mind is one that has

“an extraordinary power to hold in mind an extremely complex collection of objects, provided these are sensory objects having shape and color that the imagination can visualize, second, an incapacity for abstraction and generalization, even going so far as a deep aversion with regard to these intellectual operations.”(1954, 58)

In contrast, the "supple" mind is the mind with a) the intuitive 'espirit de finesse' that produces good sense capable of sound judgment in the face of underdetermination; as well as b)'esprit de géométrie' which helps grasp a wide range of objects and at the same time abstract, generalize, and group them logically. The aim of physical theory for Duhem, was building a logically coordinated classification of empirical laws, and so both the espirit de finesse and espirit de géométrie played important roles. The supple mind can "grasp simultaneously the whole and the details"(1954,61). He says in German Science, that good sense "will intervene at the moment at which one realizes that the consequences of a preconceived idea are either contradicted or confirmed by the experiment. This realization is in fact far from being entirely simple; the confirmation or contradiction is not always explicit and straightforward, like a simple 'yes' or 'no'.” (23) Further, drawing on the example of Pasteur's experiments with rabbits which were performed to confirm his preconceived idea that on injecting a certain substance in them rabbits die; Duhem comments:

"If, then, he sees one inoculated rabbit live or one control animal die, he need not conclude 
directly and overtly to the falsity of his preconceived idea. He could be faced with some accident of the experiment which need not require the abandonment of his idea. What will determine whether these failures are or are not of such a nature that the supposition in question must be renounced? Good sense. But this judgment will be of just the same type as a judgment in a legal proceeding wherein each of the two parties is faced with evidence some of which tends towards conviction and some towards exculpation. Good sense will not return its verdict until after having weighed the pros and cons with mature consideration.”(1991, 24)

Now all this - finesse, judgment, mature consideration - certainly strikes me as talk of "stable dispositions" in Greco's sense of the term, that reflect the cognitive character of the scientist. Duhem takes pains to carefully describe the mind of the physicist and discuss beliefs and attitudes in terms of cognitive character traits and not the other way round. i.e., Duhem talks of legitimacy of beliefs in terms of cognitive character traits; he does not talk of the traits or "epistemic virtues" so to speak, in terms of the validity of beliefs. For instance, he says about those not interested in seeing a unified and coordinated system of classification of laws erected which he took to be a very important indication of a theory's approaching natural classification that such minds are the ample and weak ones that "fear" abstraction and generalization. (1954, 102) He goes on to say that "Those very physicists who have developed theories whose various parts cannot be fitted together.... have done so only reluctantly and with regret." $(1954,102)$ Further: "Only those who affect a hatred of intellectual strength were mistaken to the extent of taking the scaffolding for a completed building." $(1954,103)$ Such statements clearly show that Duhem turns traditional non virtue-theoretic epistemology on its head and makes cognitive character traits basic. Another interesting parallel between Greco's agent reliabilism and Duhem is that both hold that virtues/ good sense are part intuitive, and part cultivated. Greco says, 
"knowledge and justified belief are grounded in stable and reliable cognitive character. Such character may include both a person's natural cognitive faculties as well as her acquired habits of thought." $(1999,287)$. And Duhem notes in both German Science and in Aim and Structure that while good sense is born out of the intuitive 'espirit de finesse', it nevertheless gets perfected by the study of history, by our becoming more aware of the failures and successes of previous theories, by thinking about the trajectory of scientific theories.

Moreover, Duhem's view that hypotheses "germinate" in a mind that has been made conducive $(1954,252-257)$ reinforces an agent reliabilist reading of him. Duhem firmly believed that a physicist should have studied the historical developments of theories. Comparing the birth of a hypothesis to the germination of a seed, he says "a preliminary labor has made favorable the ground in which the seed fell; it has made possible the accelerated development..." (ibid., 254) He says of Oersted's contributions to electrodynamics for instance, that he was "remarkably well prepared to receive it, nourish it, and develop it.” (ibid., 254) Further:

"Contemplation of a set of experimental laws alone does not, therefore, suffice to suggest to the physicist what hypotheses he should choose in order to give a theoretical representation of these laws; it is also necessary that the thoughts habitual with those among whom he lives and the tendencies impressed on his own mind by his previous studies come and guide him, and restrict the excessively great latitude left to his choice by the rules of logic.” (ibid., 255)

So good sense definitely seems to qualitatively fit the agent reliabilist picture. But the central, specific question this paper purports to address is, did good sense justify theory choice? As outlined in Section 2, Ivanova claims that good sense for Duhem is just a post hoc explanation of theory choice, not a justification for it. I briefly stated my argument against this 
idea there, and will elaborate on it here. Duhem's thesis of good sense can be seen as explanatory: the thesis can be seen as explaining how a theory or hypothesis reasonably and justifiably gets picked out in in the face of empirical uncertainty. The explanation is that good sense directs and justifies this choice. However, Duhem seems to have been a realist about this explanation. I.e., he took this explanation to be true. This means that according to him, good sense really does bring about and justify theory choice - in fact, as suggested in the German Science quote above which says good sense "intervenes"; good sense is causal: it is responsible for theory choice. Good sense for Duhem is but a feature of the supple mind. It is not introduced all of a sudden as a new idea to just "save the (meta)phenomenon" of theory choice during underdetermination. It is a smooth and natural continuation of Duhem's views on the mind of the theorist, which he articulates way before he comes to this problem of underdetermination, (in Chapter IV) in Aim and Structure.

There is ample evidence for my view that Duhem took good sense as justifying theory choice. Duhem says we can "very properly decide" $(1954,217)$ between multiple theory choices using good sense. Further, he says good sense comes out so clearly "in favor of" (ibid., 218) one of the choices that the other side gives up the struggle (even though, he goes on to say, pure logic would not forbid its continuation) - again implying that we are compelled to accept its judgment even before future experiment can ratify the choice. He goes on to say regarding a good sense based judgment that a certain theory is to be discarded, "Pure logic is not the only rule for our judgments; certain opinions which do not fall under the hammer of contradiction are in any case perfectly unreasonable." (1954, 217) Also as in the German Science quote earlier, he says "Good sense will not return its verdict until after having weighed the pros and cons with mature consideration." How do we understand such language? If an epistemic choice is proper, forceful, 
reasonable, and based on mature consideration, I don't see any reason we cannot properly construe it as being justified.

What is the nature of this justification? It is reliabilist, as opposed to evidentialist. In particular, it is agent reliabilist. As in Section 3, agent reliabilism takes justification to be grounded in the cognitive character and successful and stable dispositions of the cognitive agent. This seems to apply very well to Duhem: theory choice according to him is grounded in and justified by good sense, an epistemic virtue: a stable and successful disposition that is part intuitive, part cultivated. Greco quotes Sosa in support of agent reliabilism, according to whom, just as in Virtue Ethics primary justification attaches to the virtues of the moral agent, and secondary justification to particular deeds based on those virtues, in VE, "primary justification would apply to intellectual virtues, to stable dispositions for belief acquisition, through their greater contribution toward getting us to the truth. Secondary justification would then attach to particular beliefs in virtue of their source in intellectual virtues or other such justified dispositions." (Sosa quoted in Greco, 1999, 287) Along these same lines, what comes through in all those detailed characterizations of the different kinds of minds and "spirits" ("espirit de finesse' and 'espirit de géométrie') by Duhem is that primary justification (or the lack of it) attaches to the minds and associated virtues (or vices). Secondary justification attaches to decisions made based on those virtues: a certain theory is secondarily justified owing to its epistemic source - good sense - being primarily justified. Justification for good sense is for Duhem prior to the justification for theory choice: good sense is justified since it is just its nature to "weigh pros and cons with mature consideration" - and since theory choice comes out of it, it is in turn justified.

What then is the role of evidence - here, novel predictive success? How does that fit into 
this story? Duhem does in fact hail novel predictive success many times in Aim and Structure. He calls it the "highest test" $(1954,28)$ of holding a physical theory as approaching a natural classification. How to accommodate this in the agent reliabilist story? According to Ivanova, novel predictive success alone justifies theory choice for Duhem. According to Fairweather's reading of Duhem, while good sense confers uniqueness on a theory and puts other contenders out of the running, only novel predictive success confers 'fundamental epistemic standing' on a theory. I will offer a textual interpretation of Duhem's take on the role of novel predictive success in a bit, but before that a clarification is in order.

Fundamentally, I think that there is no tension between giving an important epistemic consideration for novel predictive success on the one hand, and seeing good sense as an agent reliabilist virtue on the other. Recall Greco's arguments: Apparent lining up with evidence alone cannot justify a belief since owing to Hume's Problem of Induction we could never trust our evidence. We need some sort of reliabilism. Simple reliabilism won't do owing to problems of a) the so-called fleeting processes, and b) subjective justification. Hence he argues, agent reliabilism is the way to go. However, will a false belief stemming from stable and successful dispositions count as knowledge according to agent reliabilism? For instance - taking the simple case of perceptual judgment - will the belief that a coiled rope is a snake count as knowledge? Greco doesn't consider such cases explicitly but I think it is highly unlikely that he would consider such beliefs to be knowledge even if they stemmed from very reliable, i.e. stable and successful, dispositions in the most virtuous (conscientious, perspicacious etc.) agent. So over and above its source, a belief's lining up with evidence would presumably be required for counting it as knowledge. As I read Greco, agent reliabilism's focus seems to be on the point that apparent lining up with evidence is necessary but not sufficient for knowledge and justification. 
(Or some might say it is probably sufficient for justification but certainly not for knowledge.) My point is, according an important epistemic role for evidence does not collapse agent reliabilism into evidentialism - it does not undermine it in any way. As long as we say that a person's reliable epistemic virtues also play a necessary role in knowledge and justification, agent reliabilism is on firm ground. In the context of Duhem then, requiring a theory that is a product of good sense to make successful novel predictions doesn't undermine an agent reliabilist reading of good sense; as long as it is clear that for Duhem, good sense is necessary to produce the theories.

Now did Duhem in fact think good sense played a necessary role in theory choice? I believe he did. There is textual evidence for Duhem having taken good sense to be empirically necessary to produce theories that will tend to a natural classification. This should already have been clear from the quotes presented in the beginning of this section. But consider in addition the following revealing passage in German Science. Duhem tells us that good sense is not simply a capacity that comes into play during underdetermination: it enters the scene much earlier. Good sense directs the very construction of a theory, even before it is put to experimental test. Recall that for him the logical coordination and unity of theories is very important. And good sense is necessary for this:

"In order to draw out of the preconceived idea consequences that can be compared with facts, which experimental proof will either confirm or condemn, one must deduce. Such deduction is often a quite long and delicate process. It is essential that it be a rigorous process, under pain of making the observational testing depend upon propositions which could not be derived from the hypothesis, and thus of rendering this testing illusory. This reasoning, however, cannot in general be conducted more geometrico, under the form of a series of theorems. The proposition 
whose consequences one wishes to deduce would not lend itself to this process. The ideas on which it depends are no longer highly abstract but quite simple concepts, like the first objects of the mathematical sciences, or ideas made in a well-known fashion by definition using those concepts. These are ideas richer in content but less precise, less analysed; they issue more immediately from observations. To reason exactly with such ideas, the rules of syllogistic logic are not adequate. They must be assisted by a certain sense of soundness that is one of the forms of good sense.” $(1991,23)$

Here I would like to quickly respond to Ivanova's point that Duhem did not advance good sense as a method of science. She claims $(2010,62)$ that Duhem developed a deductive account of scientific method involving the following four steps: “"(1) the definition and measurement of physical magnitudes; (2) the selection of hypotheses; (3) the mathematical development of the theory; (4) the comparison of the theory with experiment' (ibid., p. 21)." (ibid., 62) She goes on to say that good sense does not determine the construction of a theory and does not justify it. But the above quote from German Science directly contradicts Ivanova's point: Duhem did see good sense as a part of the scientific method - in fact, an important part of it. And he expressly denies that the scientific method is all deductive. Good sense is for him indeed necessary to construct and choose a theory. Just because Duhem's account of good sense is thin as Ivanova rightly points out, the thinness does not in any way undermine the role of good sense in theory construction and choice.

We should note here though that the kinds of necessity of reliability are different for reliabilism and Duhem's picture. Given Hume's Problem of Induction, the reliability of one's source of belief is logically necessary if we want to avoid skepticism and want knowledge and justification to be possible. Reliabilism is premised on the idea that we do want to have 
knowledge and justification and want to avoid skepticism. For Duhem, if natural classification is to be possible, good sense is empirically necessary to produce theories that will tend towards natural classification: it is a contingent fact of the physicist's life that she needs to exercise good sense in order to produce theories that will tend towards natural classification. And for Duhem this is premised on the view that we do want natural classification and want to avoid the idea that our theories are mere instruments, just classifying empirical laws efficiently ${ }^{3}$. I present below this comparison between reliabilism and Duhem's picture in a table.

Table 1

\begin{tabular}{|l|l|l|}
\hline Epistemological Position & (Agent) Reliabilism & Duhemian Good Sense \\
\hline Ultimate requirement & $\begin{array}{l}\text { Possibility of knowledge and } \\
\text { justification; avoidance of } \\
\text { skepticism in order for us to } \\
\text { feel at home in the world. }\end{array}$ & $\begin{array}{l}\text { To believe that theories tend } \\
\text { toward a natural classification, } \\
\text { and are not merely instruments } \\
\text { classifying empirical laws - in } \\
\text { order for the physicist's life to } \\
\text { be motivated and make } \\
\text { pragmatic sense. }\end{array}$ \\
\hline $\begin{array}{l}\text { Condition for satisfying above } \\
\text { requirement }\end{array}$ & $\begin{array}{l}\text { Beliefs should stem from } \\
\text { cognitive sources that reliably } \\
\text { get us knowledge and } \\
\text { justification. }\end{array}$ & $\begin{array}{l}\text { Theories should stem from } \\
\text { good sense that reliably gets } \\
\text { us closer to natural } \\
\text { classification. }\end{array}$ \\
\hline $\begin{array}{l}\text { Evidence required for belief/ } \\
\text { theory to be completely } \\
\text { justified and count as } \\
\text { knowledge/ tending towards } \\
\text { natural classification; over and } \\
\text { above stemming from reliable } \\
\text { cognitive sources }\end{array}$ & $\begin{array}{l}\text { Correspondence to the world: } \\
\text { based on corroboration/ } \\
\text { consensus/ validation... }\end{array}$ & Novel predictive success. \\
\hline
\end{tabular}

In other words, the motivation for (agent) reliabilism is to come up with a good epistemological story as to how knowledge is possible. Non-skeptics want knowledge. If we want knowledge,

\footnotetext{
${ }^{3}$ See Bhakthavatsalam (2015) for an argument for this view that Duhem valued the idea of natural classification since he thought it pragmatically benefitted the life of the physicist: it made her pursuit of physical theory meaningful, rational, and sensible.
} 
reliabilism is logically necessary. Specifically, agent reliabilists take stable and successful dispositions of a cognitive agent to be necessary for producing justified beliefs. (Note that while reliability itself is logically necessary for knowledge to be possible as pointed above, this latter necessity of stable and successful dispositions isn't logical: it is based on a need to rule out certain cases of belief formation like the case of fleeting processes as instances of producing knowledge.) Agent reliabilists believe theirs to be the correct story. In parallel, the motivation behind the concept of good sense is to come up with a good story as to how theory choice comes about. Duhem wants natural classification. And according to him good sense is empirically necessary for producing and choosing theories that will tend to a natural classification. And Duhem believes this to be the correct story about theory choice.

There is one point of disconnect between (agent) reliabilism and Duhemian good sense that I briefly touched on above, but would like to elaborate on here. According to Greco if for instance a person reliably dreamed up right beliefs all or most of the time - not consciously exercising any epistemic virtues or dispositions - those beliefs wouldn't count as knowledge. Hence clearly for him, epistemic virtues are a necessary part of justification since we don't want to count such cases of lucky accidents as knowledge. But we are unable to make this exact parallel in the case of Duhem. In a situation where a physicist dreamed up theories (or chose theories in the face of underdetermination) that are logically unified and make successful novel predictions without the use of good sense; would Duhem consider such theories to be justified i.e. approaching a natural classification? Given the empirical constraints of how our minds in fact function, without good sense, one cannot make the right choices. For instance the ample and weak minds that lacked good sense, are incapable of producing theories that will tend to a natural classification. But in the case of a hypothetical world with no such constraints where one 
dreamed up the right choices, it isn't clear from his writings what Duhem's take would be. However, I'd like to point out that in the case of ordinary (say perceptual) judgment, there are relatively more solid means to confirm the truth of a belief independent of the cognitive source (like virtues) of the belief - by others' testimonies, consensus etc. But in the case of a physical theory approaching natural classification, we don't have ways of doing this. Duhem held that novel predictive success strengthened our intuition that a theory was approaching natural classification, but was no guarantee of it. So presumably for him over and above novel predictive success, being produced by good sense was necessary to further reinforce that intuition - for recall that for Duhem good sense not only picked out a theory during underdetermination, it also helped construct it in a logically unified way - and for Duhem this logical unity was another strong indication of approaching natural classification.

Here is a last point before moving on to a closer reading of Duhem's text on the role of novel predictive success. In addition to the argument from reliabilism, Fairweather (2011) advances another argument against Ivanova's "deflation of good sense": the position that good sense does not lend any epistemic strength or justification to the chosen theory. The argument is that if good sense were indeed merely explanatory and post hoc as Ivanova claims, and not justificatory, then we are free to imagine a case where good sense doesn't intervene at all. After all, if good sense explains theory choice and there is no choice being made - i.e. if there's no explanandum - we don't need an explanation. So let us suppose that we don't make any choice in the face of a current "first level" underdetermination - i.e. a situation where multiple theories account for the current empirical facts equally well - and just wait for a future novel prediction to make a choice. This might not be the most efficient way to choose a theory, but let us assume we do this nevertheless - for according to Fairweather, Ivanova's objection should imply the 
possibility of this solution. Fairweather rightly points out that in this situation we might again end up with an underdetermination: what if all competing theories pass the novel prediction test as well? Therefore, Fairweather argues, good sense must play an important epistemic role above mere explanation, in the face of such a "second level" underdetermiantion. But he goes further than that and says that without it, we would never end up with a determinate choice, even with new confirming evidence.

Fairweather is ignoring something here: the underdetermination could be transient, and future evidence could pick out a theory, however small the probability. The merit of good sense on my reading of Duhem does not lie in the inability of novel predictions to single out a theory. Even if future evidence clearly picks out one theory, this on my reading of Duhem, would be entirely independent of the role that good sense played in picking it out first. This is because as discussed above, novel predictive success is only an indicator of natural classification, not a guarantee of it: so it seems like for Duhem, being a product of good sense is an important ingredient in the belief that the product is approaching a natural classification.

Now onto Duhem's words on the role of novel predictive success: Why, as cited by Ivanova, does Duhem insist that despite good sense, it is a successful novel prediction that has the final word? Why does he repeatedly (Chapters II, IV, VI of Aim and Structure) say that experiment alone justifies adoption of a theory and that a physicist cannot be condemned on logical grounds if she chooses not to exercise her 'espirit de finesse' or chooses theories that are not logically unified and incompatible with each other $(1954,102)$ ? For instance why does he, in the context of resolving underdetermination say in as many words that the methods of the physicist "are justifiable only by experiment" ${ }^{\text {"? }}$ (217, emphasis mine.) I contend that throughout

\footnotetext{
${ }^{4}$ It is well known that Duhem problematized the relationship between theory and experiment: he
} 
Aim and Structure, Duhem seems to have two distinct, non-intersecting epistemologies: one of physics - which seems evidentialist, and one outside of physics - which seems agent reliabilist. Duhem was a physicist-philosopher. He frequently claims that although there are absolutely no epistemic resources within physics for us to believe that physical theory latches on to a natural underlying order, we are forced to believe so by various factors outside of physics, logic and reason. It is worth noting that Duhem cites Pascal as saying that we sometimes believe for 'reasons that reason does not know', both in the context of theories converging on to a natural classification as well as in that of good sense during underdetermination. About the former, he says: "The opinion is a legitimate one because it results from an innate feeling of ours which we cannot justify by purely logical considerations, but which we cannot stifle completely either." $(1954,102)$ Further he says:

"No language is precise enough and flexible enough to define and formulate them; and yet, the truths which this common sense reveals are so clear and so certain that we cannot either mistake them or cast doubt on them; furthermore, all scientific clarity and certainty are a reflection of the clarity and an extension of the certainty of these common-sense truths." $(1954,104)$

Duhem attributes similar patterns of thinking to good sense we well. For instance, as quoted earlier he says that good sense comes out "so clearly in favor of" $(1954,218)$ one of the multiple options in an underdetermination scenario. Given Duhem's commitment to the moral

famously underlined the theory laden-ness of experiment, and that - as pointed out at the beginning of the paper - there is no 'crucial' experiment in physics; an isolated hypothesis can never be confirmed or disconfirmed by theory. While a theory is being constructed, single hypotheses cannot be tested. He however emphasized that once a theory is logically completed, its conclusions - but not its fundamental postulates and intermediary steps - have to hold up to experimental test: the "comparison between the conclusions of theory and the truths of experiment is... indispensible, since only the test of facts can give physical validity to a theory." $(1954,206)$. While an isolated hypothesis could never be tested, it is nevertheless imperative for Duhem, to test the "whole of theory" with the "whole of experimental facts" $(1954,208)$ - while as I'm arguing here, operating within the domain of physics. 
goodness and the intellectual acuity of the supple, strong and narrow minds, it is very unlikely that he thought that epistemic ends alone justify the means (here, successful novel prediction alone justifying that which chose the theory, i.e. good sense). It seems that for Duhem, theories that arise from good sense are justified from an agent reliabilist perspective. The justification Duhem talks about when he says that the methods of the physicist are justified by experiment alone - an apparently evidentialist view - should be considered when we are strictly within the confines of physics and its prescribed methods: here it is Duhem qua physicist speaking. But from a broader, philosophical perspective, Duhem rather means, I think, that while experiment further validates theory choice, as I've argued above, good sense is a necessary part of that choice. Based on all his discourse on the different kinds of minds, strongly praising some and reprimanding others, it seems clear that Duhem wants the physicist to be sensitive to the reliability of the source of her theories - and this idea is central to agent reliabilism. For Duhem the reasons for which the physicist chooses a theory are grounded in her good sense. However, the successful novel prediction will no doubt further vindicate the choice. In a sense then we might consider Duhem to have been a voluntarist about the role of the concepts of good sense and natural classification: when wearing the physicist hat, we have no reason to consider these ideas; but when we take a step back and look at the big picture - when we wear the philosopher's hat if you will - we have no choice but buy into these ideas of natural classification and good sense.

I contend then that good sense confers not just uniqueness, but actually does determine theory choice, also providing (an agent-reliabilist) justification. Good sense doesn't simply pick one and put the rest "out of the running". It is not just something that prevents the proliferation of acceptable theories. Good sense provides a sound epistemic basis for the uniqueness. With 
this, I hope to have convinced the reader that no Fairweather-type hybrid reading of Duhem is required. Duhemian good sense fits quite comfortably into a purely agent reliabilist picture.

\section{The Problem of Induction: Duhemian Reliabilism vs. Popperian Falsification}

I will conclude with some exploratory remarks on the value of reliabilism for a scientific realist position. Karl Popper (1959) famously held that science does not involve any induction. He thought that Hume was right about the Problem of Induction, but that science never faced it since it didn’t involve any induction. According to Popper, no finite evidence could ever suffice to warrant belief either that theories were true (or approached the truth), or that theories were (forever) empirically adequate. He thus believed that theories could only be tentatively accepted based on corroboration (as opposed to confirmation). A corroborated theory is one that has not yet been falsified. But of course, as many philosophers - notably Lakatos (1970), Kuhn (1962), and Putnam (1974) have pointed out, this is far from real scientific practice. In reality scientists hardly abandon a theory at first sign of falsification, in fact they even often adopt a falsified theory until a better alternative is available.

I think there might be an interesting resolution to the Problem of Induction in scientific practice to be found based on the foregoing arguments for an agent reliabilist reading of Duhem. Recall that reliabilism was advanced in response to the Problem of Induction, in order to avoid skepticism. In parallel, we could adopt a reliabilist position in the context of scientific practice, that could avoid us having to eschew any goals of truth in science. Yes, strictly speaking no amount of evidence suffices for us to have a positive epistemic attitude towards our theories, but as Samir Okasha (2002) notes, in reality scientists often do want to believe that their theories are progressively latching on to some truths. In a similar vein as noted earlier Duhem thought that 
believing that physical theory approaches a natural classification, although does not hold water strictly within the confines of logic, has pragmatic benefits for the life of the physicist: it motivates her pursuit of physical theory and makes the pursuit sensible and rational. Within the strict confines of logic, nothing can reassure us that we are in fact reaching this goal. For Duhem, novel predictive success and logical coordination and unity of a theory "strengthens our intuition" that the theory is tending towards a natural classification, but is of course no guarantee. Hence if we assume that the mind of the physicist reliably produces theories that tend towards natural classification, it more strongly reinforces the belief that our theories do in fact tend towards natural classification. Duhem worked with the idea of natural classification rather than some grander version of truth, but one might extend this argument to support any kind of realism: a good reliabilist story about the production of scientific theories might be able to effectively get us out of the Problem of Induction in scientific practice 5 .

\section{Conclusion}

I have argued that a proper agent reliabilism accommodates Duhem as a virtue epistemologist very well and shows us that good sense does offer justification for theory choice. Importantly, I have shown that it is certainly not a post hoc explanation but a part and parcel of Duhem's overall views on the mind of the physicist. Ivanova is mistaken in arguing that good sense does not provide justification. Fairweather's hybrid reading is inadequate as well for it ignores the justification offered by a proper agent reliabilist reading of good sense. Finally, based on an agent reliabilist reading of Duhem, I explored the role that reliabilism in general could play

\footnotetext{
${ }^{5}$ Along somewhat similar lines Stathis Psillos (1999) discusses the reliability of Inference to the Best Explanation - and of ampliative reasoning in general - in support of the No Miracles Argument for scientific realism (although he makes no reference to agent reliabilism).
} 
in a defense of scientific realism.

\section{References}

- Bhakthavatsalam, Sindhuja (2015) “The Rationale Behind Pierre Duhem's Natural Classification" Studies in the History and Philosophy of Science. Vol. 51 pp. $11-21$.

- Duhem, Pierre. (1954) The Aim and Structure of Physical Theory. Princeton: Princeton University Press.

- Duhem, Pierre. (1991) German Science: Some Reflections on German Science/ German Science and German Virtues. Open Court Publishing Company, La Salle.

- Greco, John. (1999) ‘Agent reliabilism’. In Philosophical Perspectives 13, 273-296.

- Greco, John, and Turri, John "Virtue Epistemology", The Stanford Encyclopedia of Philosophy (Winter 2016 Edition), Edward N. Zalta (ed.), URL = $<$ https://plato.stanford.edu/archives/win2016/entries/epistemology-virtue/>.

- Ivanova, Milena. (2010) "Pierre Duhem's good sense as a guide to theory choice". Studies in History and Philosophy of Science 41, 58-64.

- Fairweather, Abrol. (2011) "The Epistemic Value of Good Sense”. Studies in the History and Philosophy of Science 43 (1), 139-146.

- Kuhn, Thomas (1962) The Structure of Scientific Revolutions. Chicago: University of Chicago Press.

- Lakatos, Imre (1970) "Falsification and the Methodology of Scientific Research Programmes." In Criticism and the Growth of Knowledge, edited by Imre Lakatos and Alan Musgrave, 91-196. Cambridge: Cambridge University Press.

- Okasha, Samir (2002) Philosophy of Science: A Very Short Introduction. Oxford University Press.

- Popper, Karl (1959) The Logic of Scientific Discovery. London: Hutchinson.

- Psillos, Stathis (1999) Scientific Realism: How Science Tracks Truth. Routledge.

- Putnam, Hillary (1974) “The 'corroboration' of Theories." In The Philosophy of Karl Popper, edited by Paul Arthur Schilpp, 221-40. Open Court Publications, La Salle.

- Stump, David. (2007) "Pierre Duhem's Virtue Epistemology". Studies in History and Philosophy of Science 38, 149-159. 
